\title{
Healthcare waste generation and its management system: the case of health centers in West Gojjam Zone, Amhara Region, Ethiopia
}

\author{
Muluken Azage ${ }^{1}$, Abera Kumie ${ }^{2}$
}

\begin{abstract}
Background: Healthcare service providers generally aim at controlling and preventing diseases such as communicable ones. However, in the course of activities, the generation of hazardous and non hazardous waste is a concern of an environmental risk to health care workers, the public and the environment at large.

Objective: To assess healthcare waste type, generation rate, and its management system in health centers in West Gojjam Zone.

Methods: Cross-sectional study was employed to estimate waste generation rate and evaluate its management system in ten public health centers from March 2007 to April 2007. Observational checklist, key informant interview guide and weighing scale were data collection tools that were used to characterize waste generation. Weighing of healthcare waste was done for eight consecutive days in each health center. Data were entered and analyzed using EPI Info version 6.04d and SPSS version 13.0.

Results: The daily mean $( \pm \mathrm{SD})$ healthcare waste-generation rate was $1.79 \pm 0.54 \mathrm{~kg}$, which was equivalent to 0.035 $\pm 0.05 \mathrm{~kg} /$ outpatient/day. About $0.93 \pm 0.3 \mathrm{~kg} /$ day $(52.0 \%)$ was general and $0.86 \pm 0.33 \mathrm{~kg} / \mathrm{day}(48.0 \%)$ was hazardous waste. The mean healthcare waste generation rate among health centers did not significantly vary. Segregation of wastes and pre treatment of infectious wastes were not properly practiced by any of the health centers. Only four out of ten health centers used local type of incinerators, while others used open burning for the final handling of healthcare wastes. Biological wastes such as placenta were generally disposed and buried in nonwatertight disposal pits. Operational guidelines were not found in all assessed health centers. Nine out 70 (13\%) interviewed healthcare workers had needle injuries during the last 12 months prior this study.

Conclusion: The unit generation rate was relatively small in magnitude when compared with similar health facilities that are found in developing countries. The indiscriminate handling and disposal of biological wastes is a concern.
\end{abstract} [Ethiop. J. Health Dev. 2010;24(2):119-126]

\section{Introduction}

Healthcare institutions provide medical care comprising of diagnostic, therapeutic, research, and rehabilitative services in an attempt to manage health problems and protect the public from different health risks. In the process of performing these activities, health facilities generally generate hazardous waste that could be potentially harmful to health care workers, the public and the environment $(1,2)$.

The generated waste from health facilities is categorized in to two categories: general (non-hazardous) and hazardous waste. General wastes does not pose risk of injury or infections under a conditions they are generated. Their nature is generally similar to household related wastes. Hazardous waste is one whose health outcome is related to undesired biological and chemical health damages in the course of its management (1-3).

There are various estimates regarding to hazardous and non-hazardous constituents of healthcare waste. According to a World Health Organization (WHO) related reports and studies, around $85 \%$ of hospital wastes are non-hazardous, $10 \%$ are infectious (hence, biological hazardous), and the remaining $5 \%$ are toxic chemicals, pharmaceutical and radioactive wastes (3-6). This traditional estimate, however, is not consistent for many developing countries. The proportion for hazardous waste varied from country to country: Pakistan a bout $20 \%$, Nigeria $26.5 \%$ and in Sub-Saharan Africa countries about $2-10 \%(2,7,8)$. In Bangladesh, $36.03 \%$ in diagnostic centers and higher clinics; and about $50 \%$ in urban health centers of Tanzania constituted hazardous waste $(9,10)$.

The characteristics of waste generation depends on number of factors such as established methods of waste management, type of healthcare establishment, degree of health facility specializations, proportion of reusable items employed in health care, seasonal variation and patient work load. In middle and low-income countries, healthcare waste generation is usually lower than that of high-income countries $(2,4,8)$.

Urban and rural hospitals and clinics in developing countries dispose their medical waste in a manner that pose a risk of diseases among populations. In 2002, the results of a $\mathrm{WHO}$ assessment conducted in 22 developing countries showed that the proportion of healthcare

${ }^{1}$ Madawalabu University, Health Science College, Bale Goba, Muluken Azage, mulukenag@yahoo.com

${ }^{2}$ Addis Ababa University, School of Public Health, Faculty of Medicine, Abera Kumie, aberakumie2@yahoo.com 
facilities that did not use proper waste management was significant, ranging from $18 \%$ to $64 \%$ (11).

A study done on Healthcare waste generation in government Health facilities of Dare-Salaam (United Republic of Tanzania) in 1995/1996 showed a generation of $0.02 \mathrm{~kg} /$ day per outpatient in a studied urban health centers $(10,12)$. The wastes were left in the open space for one to two days. There was no clear guidance to segregate wastes and ensure their proper disposal. Healthcare waste was primarily carried by open bucket as respondent mentioned (44.38\%) and plastic bowl $(23.86 \%)$. The study concluded that there was a lack of knowledge and interest in safe waste disposal by most health workers. In addition, the absence of adequate funding to implement waste management programs was a challenge (2).

A study which is done on medical waste in five health care institutions in Abuja, showed that waste handling was poorly practiced: $18.3 \%$ of the source points burn wastes in a locally built brick incinerator, 9.1\% bury, $36.3 \%$ burn waste in open pits, while $36.3 \%$ dispose of a waste into municipal dumpsites (7). Another study conducted in South Africa in the Kwazulu-Nata province showed that $45 \%$ of health care waste was illegally dumped, buried or burnt in the vicinity of ambient environment (13). Healthcare facilities in Swaziland do not have common standards for source separation, collection equipment for disposal of medical waste. Medical waste is generally disposed of by the use of locally made incinerators or it is simply dumped together with general waste types at landfill sites (13).

The health care waste management in Ethiopia is not much different from what was described above. The Ministry of Health in Ethiopia conducted an assessment involving 16 health centers and 48 clinics. The findings in unpublished report indicated that most of health facilities did not have proper liquid and solid waste disposal facilities (14). One study in Sidama Zone (Ethiopia) showed that 42.5\% (17 from 40) of health institutes used incinerators to handle syringes, needles and other sharp objects; $35 \%$ of these institutes collected and disposed syringes, needles or sharps in a manner that exposed workers and the general public to a health risk (15). The general population, in addition to health workers, is known to be threatened by health care waste $(6,8)$.

Significant number of health care waste is assumed to be generated in Ethiopia. A recent official statistics indicated the presence of 195 hospitals, 1375 health centers, 12,488 health posts and 2853 private clinics (16). Focused studies on unit generation and its characteristics is hardly available in Ethiopia. This study highlights a situational characterization of health care waste generation rate and its management system in Health Centers of Ethiopia.

\section{Methods}

Study design, area and population: a cross-sectional survey was conducted to quantify waste generation rate and evaluate its management system from March 2007 to April 2007 in ten health centers of West Gojjam zone in Amhara region. The population of the zone is 2,610,861, of which $92 \%$ and $8 \%$ are found in rural and urban, respectively. Public owned health facilities predominately serve the population. There are 1 hospital, 10 health centers, and 187 clinics at the time of the study. All health centers were included in this study.

Data collection: We used observational checklist with participatory approach and key informant interview guide to assess the healthcare waste management in terms of segregation, storage, collection, and treatment. Standard weighing scale was used to quantify the generation rate of healthcare waste. Questionnaire was used to assess the magnitude of needle stick injury. The frequency of daily new patients and those who had some other health services at the time the study duration were taken from OPD registers. The number of new outpatients was used to calculate the daily waste generation. Reviewed article on healthcare waste generation often considered the denominator of new outpatients who were handled by ambulatory health facilities.

Data collection procedures: First, a transient walk through inspection in each health center was done in order to identify the type of generated waste. All health service delivery sections were included for the transient observation: OPD (out patient department), drug dispensing, injection and dressing, mother and child health clinic $(\mathrm{MCH})$, family planning (FP), expanded program immunization (EPI) room, tuberculosis follow up unit, ward for emergency cases and delivery room. Health centers were grouped into three ("Adet", "Merawi", "Durbete" and "Dangila" set as first group; "Injbara", "Gimjabet" and "Chagini" set as second group and the third group was "Bure", "Sekela" \& "Shindi" health center) based on their geographical accessibility. This was useful to ensure data quality follow up at the time of data collection. Healthcare waste was collected and measured daily for eight uninterrupted consecutive days from March 5 - 26, 2007 (5 -12 for the first group, $12-19$ for the second group and $19-26$ for the third group) to characterize waste generation.

Empty plastic buckets of standard colors: blue color for general waste, green color for pharmaceutical waste and red color used for infectious waste and pathological waste were daily distributed to different section of the health center. Plastic bags with different colors (blue strip plastic bags for general waste and red strip plastic bags for infectious waste and pathological waste) were kept 
inside the respective buckets. The buckets and plastic bags were labeled to indicate the different categories of healthcare waste, the place of generation, date of collection and sample number. Waste weighing and recording station was arranged in convenient site within the vicinity of the health center. On the next day, collected wastes in plastic bags were removed every morning and the weight was measured at 8:00 am (local time) using weighing scale (Baby scale, capacity range $15 \mathrm{~kg} \&$ model 4 capacity range $20 \mathrm{~kg}$ ).

Twenty enumerators with a background of completing high school and five supervisors, who were Health Center Sanitarians, were locally recruited. A two days training was given on the purpose of the study, data quality, types of health care waste, and the use and calibration of a weighing scale. Data collection guideline was used to facilitate the training. Data were recorded daily in a suitable data sheet.

Operational definitions: Standard WHO definitions such as general waste, pathological waste, infectious waste, sharps, pharmaceutical wastes and segregation were used in this study (1).

Data quality management: Pre-test in a similar health center that was not included in our survey was conducted prior to the actual data collection time to assure accuracy and validity of the observational checklist and weighing scale. Weighing scale was calibrated using a known standard of $100 \mathrm{~g}, 500 \mathrm{~g}$ and $1000 \mathrm{~g}$ weighting objects every morning before the actual measurement started during data collection days. Calibration was made periodically as well. Training and supervisions were used to reinforce data quality.

Data management and analysis: The raw data collected from the field were entered and compiled using EPI INFO (version 6.04; Center for Diseases Control and Prevention, Atlanta, GA, USA and World Health Organization, Geneva, Switzerland), and SPSS (version
13; SPSS Inc., Chicago, IL, USA). Data cleaning was performed by running each variable to check the accuracy, inconsistency and missed value. The average daily quantity of health care wastes in the health centers was computed. Mean and standard deviation, KurskalWallis test were computed for descriptive statistical analysis. The result was presented using tables and graphs.

Ethical considerations: Ethical clearance was obtained from the then Department of Community Health, Faculty of Medicine, Addis Ababa University. Permission for data collection was obtained from Amhara Regional Health Bureau, Zonal Health Department and Woreda Health Office. Verbal and written consent from the head of each health center were also taken prior data collection. Data collectors were trained to use protective devises while handling healthcare wastes. Supervisors were made alert about the provision of medical assistance for sharps and needle prick injuries.

\section{Results}

Service, seeking and patient loads in study health centers: A total of 14,866 patients sought some kind of health service in the ten health centers, of whom 4,167 (28.0\%) patients were outpatients (OPDs). The mean \pm SD (standard deviation) patient flow per day in all sections and outpatients in each health center was 185.8 \pm 30.3 and $51.7 \pm 11.6$ patients, respectively.

Generation rate: The mean $( \pm \mathrm{SD})$ healthcare waste generation rate per health center was $1.79 \pm 0.54$ $\mathrm{kg} /$ day, of which $0.93 \pm 0.3 \mathrm{~kg} / \mathrm{day}(52.0 \%)$ was general and $0.86 \pm 0.33 \mathrm{~kg} /$ day $(48.0 \%)$ was hazardous waste. Increased amount of healthcare waste per day was generated at "Dangila" $(2.82 \pm 2.27 \mathrm{~kg} /$ day $)$ and "Chagini" ( $2.6 \pm 2.4 \mathrm{~kg} /$ day $)$ health centers, while small amount of healthcare waste was recorded at "Gimjabet" $(1.12 \pm 0.50 \mathrm{~kg} /$ day $)$ and "Shindi" $(1.16 \pm 0.87 \mathrm{~kg} /$ day $)$ health centers (Table 1$)$. Over all daily generation per outpatient was $0.035 \pm 0.05 \mathrm{~kg}$.

Table 1: Daily healthcare waste generation rate in health centers, West Gojjam, Amhara Region, March 2007.

\begin{tabular}{|c|c|c|c|c|}
\hline \multirow[b]{2}{*}{ Name of Health centers } & \multicolumn{2}{|c|}{ Healthcare Waste, kg/day } & \multirow[b]{2}{*}{$\begin{array}{l}\text { Mean of General } \\
\text { Waste }(\%)\end{array}$} & \multirow[b]{2}{*}{$\begin{array}{l}\text { Mean of } \\
\text { Hazardous } \\
\text { Waste (\%) }\end{array}$} \\
\hline & Total HCW in eight days & $\begin{array}{l}\text { Mean of HCW } \\
\text { Mean } \pm S D\end{array}$ & & \\
\hline Adet & 11.52 & $1.44 \pm 0.81$ & $0.68(47.2)$ & $0.77(52.8)$ \\
\hline Merawi & 16.56 & $2.07 \pm 1.39$ & $1.31(63.3)$ & $0.76(36.7)$ \\
\hline Durbete & 14.00 & $1.75 \pm 0.69$ & $0.75(42.9)$ & $1.00(57.1)$ \\
\hline Sekela & 12.48 & $1.56 \pm 0.79$ & $0.98(62.8)$ & $0.58(37.2)$ \\
\hline Shindi & 9.28 & $1.16 \pm 0.87$ & $0.55(47.4)$ & $0.61(52.6)$ \\
\hline Bure & 12.40 & $1.55 \pm 1.28$ & $0.81(52.3)$ & $0.74(47.7)$ \\
\hline Dangila & 22.56 & $2.82 \pm 2.27$ & $1.46(51.8)$ & $1.36(48.2)$ \\
\hline Injbara & 14.88 & $1.86 \pm 1.24$ & $0.98(52.7)$ & $0.88(47.3)$ \\
\hline Gimjabet & 8.96 & $1.12 \pm 0.50$ & $0.65(58.0)$ & $0.47(42.0)$ \\
\hline Chagini & 20.8 & $2.60 \pm 2.16$ & $1.11(42.7)$ & $1.49(53.7)$ \\
\hline Overall Mean & 14.34 & 1.79 & $0.93(52.0)$ & $0.86(48.0)$ \\
\hline SD & 4.53 & 0.54 & 0.30 & 0.33 \\
\hline
\end{tabular}


The types of hazardous waste generated from study health centers were sharps, infectious pathological and pharmaceutical waste. Radioactive waste was not observed in any of health centers. The over all mean \pm SD generation rate of sharps, infectious, pathological and pharmaceutical waste for a health center was $0.34 \pm 0.1$, $0.17 \pm 0.04,0.34 \pm 0.25$ and $0.017 \pm 0.01 \mathrm{~kg} / \mathrm{day}$, respectively. Sharps and pathological waste compose $79 \%$ of the hazardous waste (Table 2 ).

Table 2: Distribution of type and amount daily hazardous waste generation rate in health centers, West Gojjam, Amhara Region, March 2007.

\begin{tabular}{|c|c|c|c|c|c|}
\hline \multirow[t]{2}{*}{$\begin{array}{l}\text { Name of health } \\
\text { centers }\end{array}$} & Sharps* & Infectious & Pathological & Pharmaceutical & $\begin{array}{l}\text { Total } \\
\text { Hazardous waste }\end{array}$ \\
\hline & Kg/day & Kg/day & kg/day & Kg/day & Kg/day \\
\hline Adet & 0.32 & 0.16 & 0.28 & 0.01 & 0.77 \\
\hline Merawi & 0.47 & 0.13 & 0.13 & 0.026 & 0.76 \\
\hline Durebet & 0.39 & 0.19 & 0.40 & 0.019 & 1.00 \\
\hline Sekela & 0.20 & 0.20 & 0.16 & 0.016 & 0.58 \\
\hline Shindi & 0.17 & 0.15 & 0.29 & 0.003 & 0.61 \\
\hline Bure & 0.24 & 0.17 & 0.32 & 0.010 & 0.74 \\
\hline Dangila & 0.46 & 0.25 & 0.63 & 0.023 & 1.36 \\
\hline Injbara & 0.39 & 0.16 & 0.31 & 0.018 & 0.88 \\
\hline Gimjabet & 0.32 & 0.13 & 0.00 & 0.020 & 0.47 \\
\hline Chagini & 0.39 & 0.20 & 0.87 & 0.026 & 1.49 \\
\hline Average & 0.34 & 0.17 & 0.34 & 0.017 & 0.86 \\
\hline SD & 0.01 & 0.04 & 0.25 & 0.01 & 0.33 \\
\hline
\end{tabular}

Sharps* includes needles, blade, lancet needles, syringes, scalpel blades.

Variation in health care waste characteristics: The amount of healthcare waste generation rate was statistically different by health service delivery sections $\left(\mathrm{X}^{2}=229.2, \mathrm{p}<0.001\right)$ (Table 3$)$. The over all mean $( \pm$ SD) healthcare waste generation in each section was $0.224 \pm 0.22 \mathrm{~kg} /$ day. Increased amount of healthcare waste (33\%) was generated at injection and dressing room, while waste was minimal in TB follow up unit. The patient load, average health care unit generation, and the proportion of the types of waste did not vary among the ten health centers.

Table 3: Distribution and mount of daily health care waste generation rate by point sources in health centers, West Gojjam, Amhara Region, March 2007

\begin{tabular}{lccc}
\hline Departments & $\begin{array}{c}\text { HCW ( kg/day) } \\
\text { Mean } \mathbf{\pm} \text { SD }\end{array}$ & Percent & Mean rank $^{*}$ \\
\hline OPD & $0.053 \pm 0.012$ & 3.0 & 304.66 \\
Pharmacy & $0.436 \pm 0.209$ & 24.3 & 357.89 \\
Injection \& Dressing & $0.597 \pm 0.135$ & 33.3 & 545.20 \\
MCH, FP \&EPI & $0.208 \pm 0.099$ & 11.6 & 370.89 \\
Laboratory \& VCT & $0.091 \pm 0.050$ & 5.0 & 310.68 \\
TB follow up Unit & $0.007 \pm 0.007$ & 0.39 & 170.51 \\
Ward & $0.052 \pm 0.073$ & 2.9 & 207.17 \\
Delivery & $0.350 \pm 0.259$ & 19.5 & 297.01 \\
Over all mean (+SD) & $\mathbf{0 . 2 2 4 ( \mathbf { 0 . 2 2 } )}$ & & \\
\hline
\end{tabular}

${ }^{*} X^{2}=229.196, p<0.001, d f=9$

Patient load was linearly related with the daily waste generation (Spearman's correlation coefficient $=0.720, \mathrm{p}$ $<0.001)$. Linearity, however, was only consistent in four health centers ("Injibara", "Gimjabet", "Bure", "Shindi").

Waste management and related practice: All health centers used uncovered plastic buckets for the on-site waste collection. Six out of ten health centers used safety boxes for contaminated sharp collection. Plastic buckets had a size of about 10-14 liters. Neither color codes nor labeling for the type of waste was practiced.

The flow line of waste management in reference to waste minimization, segregation, storage, handling, collection, and treatment were not properly and adequately practiced by any of the surveyed health centers. Open plastic buckets and safety boxes were used to transport manually to the disposal site. Disinfection of waste storage/collection utilities was non-existent. Incinerators, burial in the health center premises (placenta pit), and 
burning in open pits were employed as a final waste disposal means.

Only four of the ten health centers had local type of incinerator. The incinerators were made of local bricks that did not have adequate air inlets for the facilitation of active waste combustion. Three of the health centers used their incinerators to burn safety boxes and office paperwaste, while one health center used an incinerator to burn all types of healthcare waste with the exception of pathological waste. The rest health institution (six out of ten) simply burned their healthcare wastes in open pits (Figure 1).

Pathological waste was handled in a non-water tight placenta pit, of which four out of ten health centers had their slab from earthen-mud while others had concrete floor (Figure 2). Free flowing liquid waste emanating from wards, laboratory and delivery rooms was simply disposed into hand washbasins that are connected to septic tank.

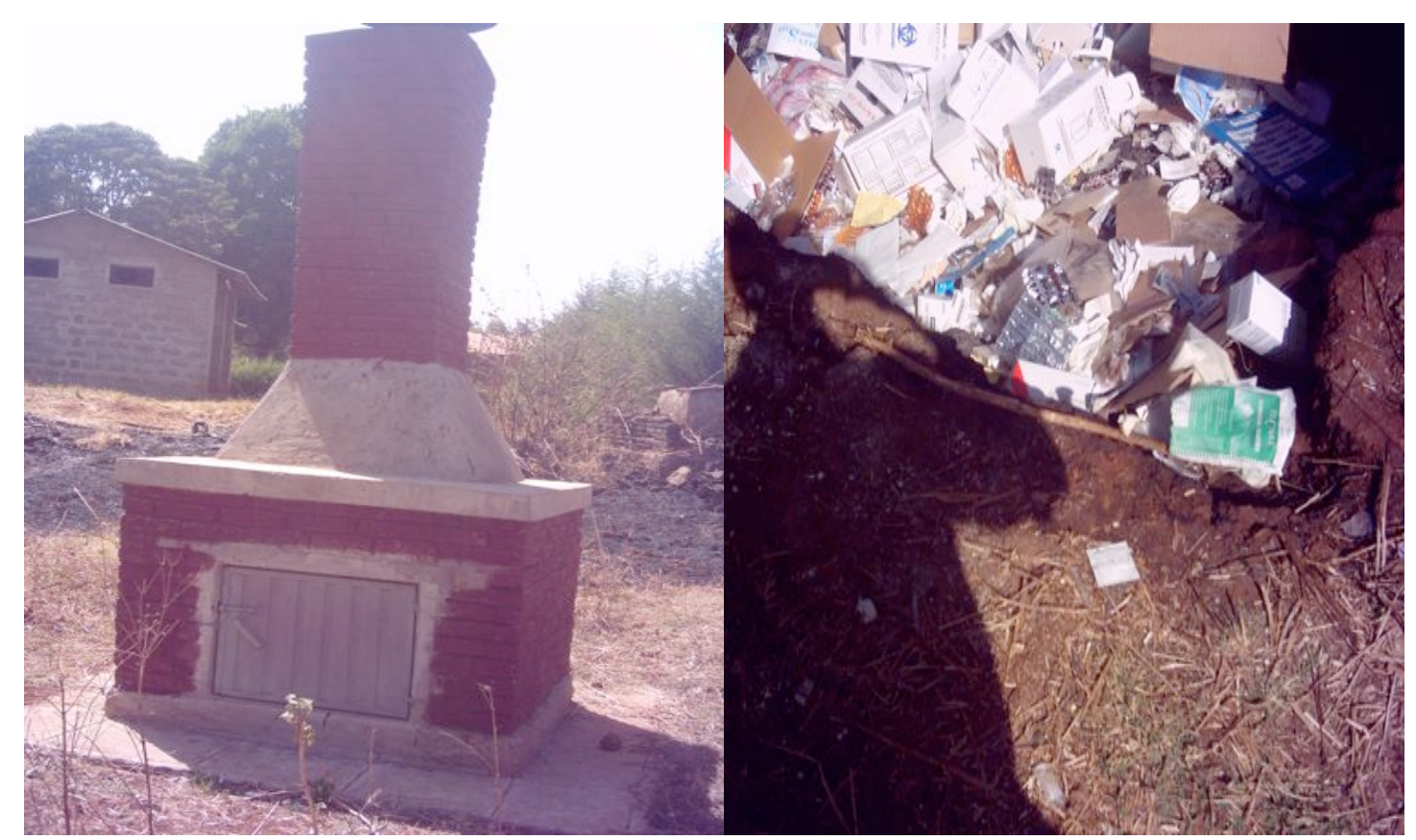

Figure 1: Newly constructed incinerator for HCW disposal and mixed disposal of HCW with open pit in study health centers.

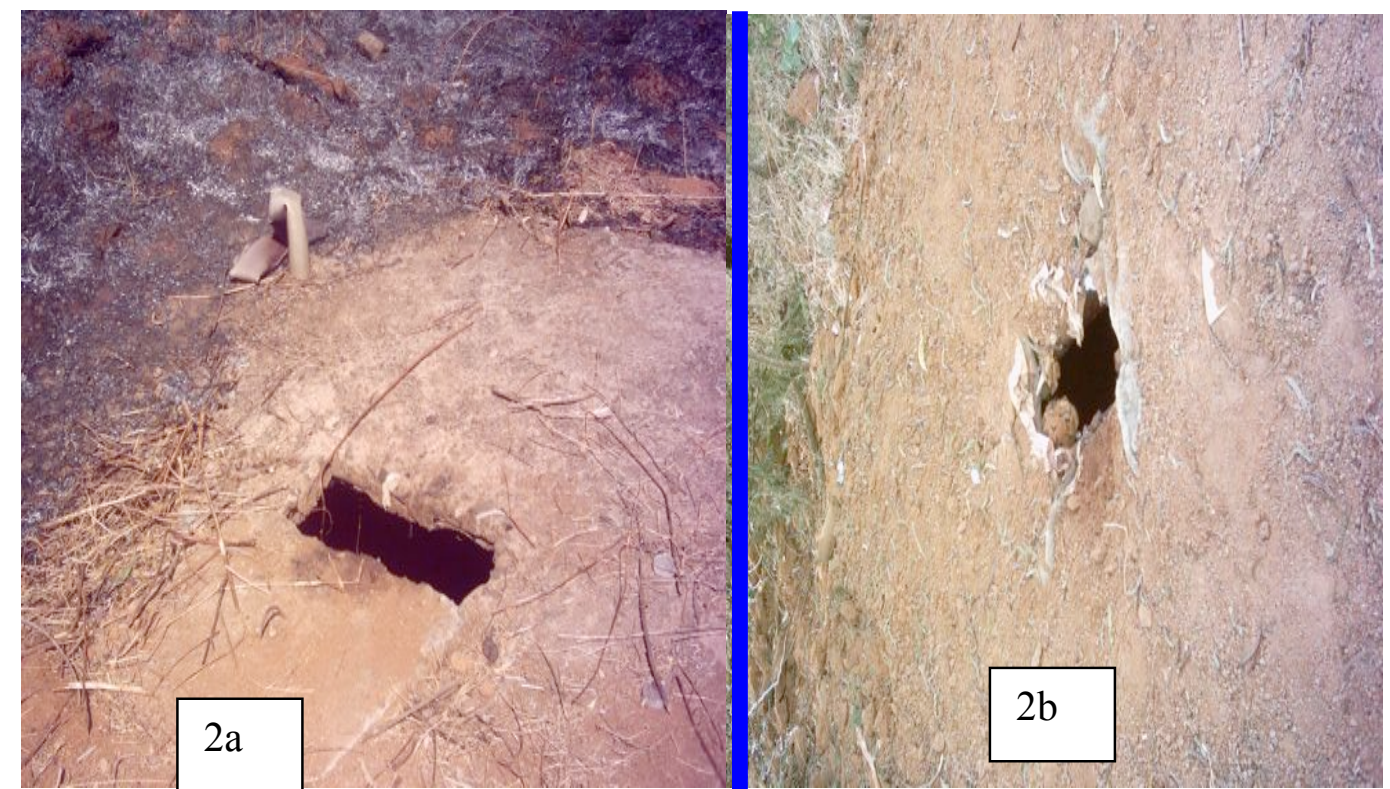

Figure 2: Placenta pits (a made from concrete; $b$ made from mud) 
Health center staffs believed that the responsibility of healthcare wastes management goes to janitors and sanitarians. Training about healthcare waste management for waste handlers was absent. Waste cleaners used heavy-duty gloves and over coat during the collection of wastes. Operational standards as well as any applicable local or regional guideline and manual for healthcare waste management and infection prevention committee were not found in the study health institutions.

\section{Knowledge of waste handlers on the risk of health care waste management: A total of 40 healthcare workers were interviewed on issue of sharp wastes, of which ten out of them $(25 \%)$ were injection providers, ten $(25 \%)$ were worked at OPD and the rest were assigned at EPI, $\mathrm{FP}$ and $\mathrm{MCH}$ room. Five out of forty healthcare workers ever had an injury for the last 12 months posed by needles and other sharps. Three of the injured had the incident because of the sudden movement of the patient while providing injection. All of them have knowledge that dirty or used needles and sharps can transmit diseases. The knowledge on the type of waste was poorly defined. Almost no healthcare workers (36 out of 40) had on-job training on healthcare waste management.}

\section{Discussion}

Issue of health care waste management is inadequately studied in Ethiopia. Information to the public on generation rates, types of waste, related environmental health risks, and problems of waste management are hardly available in local literature. Neither government nor medical facility authorities significantly pay due public attention towards the above issues. Empirical observation indicates that medical waste is handled like any other municipal waste in many urban settings of Ethiopia. Knowledge on waste characteristics is an input to the proper design and identification of technical tools of waste management. The present study contributes to fill at least a gap that is observed in waste generation characteristics.

In this study, the daily mean healthcare waste generation rate was minimal $0.035 \mathrm{~kg} /$ patient/day) and lower than the study done in Saudi Arabia in health centers and higher clinics, whose mean healthcare waste generation rate was $0.08 \mathrm{~kg} /$ patient/day (17). It was also different from another study done in Sylhet city, Bangladesh where diagnosis center and higher clinics had mean healthcare waste generation rate of $0.041 \mathrm{~kg} / \mathrm{patient} /$ day, of which $63.97 \%$ was general and $36.03 \%$ was hazardous (9). The mean of healthcare waste in this study was higher than a study done in Tanzanian urban health centers, concluding mean generation rate of 0.02 $\mathrm{kg} /$ patient/day. However, 1:1 ratio of general to hazardous waste in Tanzania was about similar with our study (10). The variation in all mean values of waste generation could be speculated to the differences in resource inputs to heath facilities, season of the year the studies undertaken, availability of different facilities, social status of the patients, healthcare waste management, legislative system of the country, and the economic strengths of each country.

The staffing pattern, patient load, and work organization in rural health centers of Ethiopia are about homogenous as they are run and evaluated by similar annual operating budgets (18). The implementation of the Health Sector Development Program is a national effort to harmonize the management of public health facilities in Ethiopia, including health centers. Further more the disease distribution served by health centers in Ethiopia is about the same with the exception of ecologically related diseases (16). These had strong implication in the similarities of daily patient flow and unit waste generation among the studied health centers. Given this contextual characteristics of waste generation, it is a surprise to observe statistical difference in waste generation rate in the sub-units of a health center. This variation is obviously due to the difference in the number of attendance in each section and type of health services delivered in each health center.

This has emanated that there is linearity between visitors and waste generation rate in the study health centers. This result is similar with other findings $(10,17)$. However, its inconsistency of linearity between health centers might be varied due to the health service demand expressed by visitors, which further determines the type of waste generated.

The result of healthcare waste-management system in this study showed that all health centers used plastic buckets with out proper cover and only six of the 10 health centers had safety boxes for collection of sharp wastes. The use of safety boxes was different from the survey conducted in 13 African countries where Ethiopia reported to handle needles in open containers in $70 \%$ of the health institutes (15). The practice was also better than the study done on injection safety in Ethiopia, which indicated the use of safety box in two of the 52 assessed health facilities (15). The growing trend in the use of safety box is an encouraging indication that the health facilities are progressing to implement the universal precautions in infection prevention and control, including HIV/AIDS with the assistance of government and NGO's resource and technical inputs.

Waste segregation and treatment are the most important interventions in the management of hazardous wastes, which, however, was poorly practiced in surveyed health centers. This finding was consistent with the survey conducted on four federal hospitals of Ethiopia $(19,20)$. In many African countries, waste disposal was reported to be a serious problem. Studies done in Cameroon, Chad, Côte d'Ivoire, Guinea-Bissau, and Uganda between 1997 and 1998 showed the complete absence of safe 
disposal of used needles and sharps in health centers (8). In Ethiopia (1997-1998), like Kenya, Rwanda and Zambia, the destruction of used syringes and needles using incineration was the commonest practice (21). Another local study conducted in health centers revealed that $42.5 \%$ (17 out of 40 ) of the health institutions used local type of incinerator to handle used needles and sharps (15). Our finding was similar with the above study in that only four out of ten health centers used incinerators and the rest six health centers used open burning for disposal of healthcare wastes. The use of open burning poses environmental risks to waste handlers and stray scavengers. Children and scavengers, who are sorting utilities to be reused or recycled, are often observed around waste collection and disposal sites.

The inappropriate practice of biological wastes such as placenta and discarded fluid wastes was similar with the study done by the Ministry of Health in Ethiopia in 1989 in 16 health centers and 48 clinics (14). The concern in this assessment included lack of proper placenta pit design and structurally suitable facility that could reduce the risk of underground water contamination and leakages to the nearby environment.

The prevalence of needle stick injury is a concern in recent times, although its documentation is grossly under-estimated (4). Empirical observation in our study indicated that $13.3 \%$ (4 out of 30 ) of waste cleaners and $12.5 \%$ (5 out of 40 ) of healthcare workers had injuries for the last 12 months by contaminated needle or sharp objects. Sudden movement of patients while handling injections, collecting used syringes and needles, and recapping of needles and syringes immediately after use were most common factors for sustaining the injuries. Needle stick injury in this study was lower than a study which reported the occurrence among $75 \%$ of the healthcare workers (18). It was also lower than the study in which sharps and needle stick injury was reported in sixty-nine (32.4\%) healthcare workers (15). Generally, the occurrence of even one needle injury in a health facility is important to consider from two public health perspectives: one it is an indication of mal practice of injection and used needle handling, and the other there is a risk of health facility acquired diseases transmission. The above pocket studies are good examples to demonstrate the health risks despite the presence of the difference in the magnitude of needle stick injuries. The fact that health care workers are aware of the risk of HIV/AIDS transmission through used needle stick in the present and other study (15) is a good indication for the practice of universal precautions that are required in diseases prevention. On the other hand, the absence of continued training and any of operating guidelines on health care waste handling and management in health centers require close attention. In-situ lack of operating guideline is consistent with other studies (18). It is known that Quality and Standard Authority of Ethiopia (QSAE) has prepared a working guideline on handling and disposal of waste materials within healthcare facilities in 2004. In 1997, Ministry of Health has also prepared similar guideline that could be practiced by all types of health facilities (22).

Lack of temporal analysis involving all months and seasons for the waste generation study and small sample size for the needle stick injury are major limitations of this study. Given this drawback, the study has presented useful data in the characterization of health care wastes in health centers. The unit generation of $0.035 \mathrm{~kg} /$ patient /day (1.79 kg/day of a health center) is relatively smaller than similar study settings. The proportion of general to hazardous waste was much different from WHO literature. Categories of sharps and pathological wastes predominated as hazardous waste, while injection and drug dispensing sites generate relatively increased health care wastes. Overall, health care waste handling and management is poorly addressed. We recommend the enforcement of standard practices of waste management in reference to the local guidelines and/or international guidelines. The institution of standard containers and bags with the indication of a universal biological hazard symbol is an urgent matter. The installation of waste management facilities (placenta pit and incinerator) should respect the immediate environment to avoid environmental risks. A proactive job of Infection Prevention Committees is highly essential.

\section{Acknowledgments}

We would like to thank Addis Ababa University, Faculty of Medicine, and School of Public Health for the financial support to carry out this research work. We are also grateful to Amhara Regional Health Bureau, Zonal Health Department and Woreda Health offices for their unreserved facilitation of data collection. Thanks also go to data collectors and supervisor for their participation in this study.

\section{References}

1. Johannessen LM, Dijkman M, Bartone C, Hanrahan D, Boyer MG, Chandra C. Health Care Waste Management Guidance Note. Washington DC: World Bank; May 2000. Available from: URL: http://siteresources. worldbank.org/HEALTHNUTRITIONANDPOPUL ATION/Resources/281627-1095698140167/ Johannssen-HealthCare-whole.pdf.

2. Akter N. Medical waste Management Review Environmental Engineering program January 2000. Available from: URL: http://www.engconsult.com/BEN/papers/Paper-anasima.PDF.

3. Halbwachs H. Solid Waste Disposal in District Health Facilities. World Health Forum 1994;15(4):363-8.

4. World Health Organization. Wastes from Healthcare Activities. WHO Fact sheet No. 253; 2000. Available from: URL: 
http:/www.phrusa.org/campaigns/aids/who 031303/unsafe.html-99k.

5. Yadar M. Hospital wastes a major problem in India. JK-Practitioner 2001;18 (4):276-282. Available from: URL: http://medind. nic.in/jab/t01/i4/jabt01i4p276.pdf.

6. Salkin IF. Review of Health Impacts from Microbiological Hazards in Healthcare Wastes. Geneva: WHO, Department of Blood Safety and Clinical Technology and Department of Protection of the Human Environment; 2004. Available from: URL: http://www.who. int/water sanitation health/medicalwaste/en/microb hazards0306.pdf.

7. Bassey BE, Benka-Coker MO, Aluyi HA. Characterization and management of solid medical wastes in the Federal Capital Territory, Abuja Nigeria. African Health Science 2006;6(1):58-63. Available from: URL: http://www.ncbi.nlm.nih.gov/pmc/articles/PMC1831 $\underline{969}$.

8. World Health Organization. Preparation of national healthcare waste management plans in sub- Saharan countries, a guidance manual Geneva: WHO; 2004. Available from: URL: http://whqlibdoc.who.int/publications/2005/9241546 62X.pdf.

9. Sarkar SKL., Haque MZ., and Khan TA. Hospital waste management in Sylhet City, Bangladesh. ARPN Journal of Engineering and Applied Sciences 2006;1(2):1-9. Available from: URL: http://www.arpnjournals.com/jeas/ research papers/rp 2006/jeas 0806 12.pdf.

10. Manyele SV. Medical waste management in Tanzania: current situation and the way forward. African Journal of Environmental Assessment and Management. Available from: URL: http:/www.ajeam-ragce.org/getdoc. asp? fpath $=\mathrm{c} ! \% 5$ cdomains.

11. World Health Organization. Healthcare waste management. Geneva: WHO; October 2004.Fact sheet No 281.

12. Prüss A, Townend WK. Teachers Guide: Management of wastes from Health care activities: WHO 1999. Available from: URL: http://www.who.int/water sanitation health/medicalwaste/guide1.pdf.

13. Leonard L. Health Care Waste in Southern Africa: A civil society perspective. Available from: URL: www.hjulmandweb.dk/ HCRWCD/Written\%20Papers/L\%20Leonard. doc.
14. Federal Democratic Republic of Ethiopia, Ministry of Health.. Report on the assessment of situations of water supply and sanitation facilities in selected health centers and health stations. Hygiene and Environmental Health Department, December 1997.

15. Yoseph W. Assessment of the Safety of Injections and Related Medical Practices in Health Institutions at Sidama Zone, SNNPR [Masters thesis]: Addis Ababa University; 2004.

16. Policy Plan and Finance General Directorate, Federal Ministry of Health. Health and Health Related Indicators. Addis Ababa: Federal Ministry of Health, 2001 EC (20008/09). On printing.

17. Al-Zahrani MA, Fakhri ZI, Al-Sahnshouri, Al-Ayed MH. Healthcare risk waste in Saudi Arabia: Rate of generation. Saudi Medical Journal 2000;21(3):245250 .

18. Fentahun M, Kedir A, Mulu A, Adugna D, Meressa D, Muna E. Assessment of antenatal care services in a rural training health center in Northwest Ethiopia. Ethiop J Health Dev 2000;14(2):155-160.

19. Environmental Health Department, Ministry of Health of Ethiopia. An assessment of the status of four Federal hospitals Infectious waste management system and hygiene practice. Unpublished report: July 2004, Addis Ababa.

20. Solomon D. A review on healthcare waste management in Ethiopia in 2005. Addis Ababa, Ethiopia, 2005. Available from: URL: http://www.saioh.org/ioha2005/ Proceedings/Papers/SSE/PaperE1-5web.

21. Dicko MS, Kone S, Pierre H, Jaequet B. Safety of immunization injection in Africa. Bulletin of the WHO 2000;78(2):163-169.

22. Disease Prevention and Control Department, Federal Ministry of Health Ethiopia. Infection prevention guidelines for Healthcare Facilities in Ethiopia. Addis Ababa, Ethiopia [cited 2004 July]; Available from: URL: http://www. etharc.org/publications/eth_inf_gdlines_jul04.pdf. 